\title{
WAITING ROOM PROJECT: IMPROVING THE CARE OF LUPUS PATIENTS THROUGH HEALTH EDUCATION IN THE COVID-19 PANDEMIC
}

Giovanna Braghini Pardini ${ }^{1}$, Pollyanna Faria Fradico ${ }^{1}$, Vitor Aurélio de Oliveira Silva ${ }^{1}$, Vitor Moreira Nunes ${ }^{1}$, Guilherme Costa Ferreira ${ }^{1}$, Nathan Shuenck Silva de Oliveira ${ }^{1}$, Juliana Lacerda de Oliveira Campos ${ }^{1}$, Clara Otoni Neves ${ }^{1}$, Luiza Silame Corte ${ }^{1}$, Agatha Oluwakemi da Silva Soyombo ${ }^{1}$, Daniel Amaral Mota ${ }^{1}$, Stela Santos Brito ${ }^{1}$, Lucas Lopes Toledo ${ }^{1}$, Caio Carvalhais Chaves ${ }^{1}$, Cristiana Afonso Leitão ${ }^{1}$, Gabriel Coelho Soares Moraes ${ }^{1}$, Henrique Trindade Dutra ${ }^{1}$, Luciana Helena Dolabela de Abreu ${ }^{1}$, Mariana Caetano Chaves $^{1}$, Débora Cerqueira Calderaro ${ }^{1, \star}$, Fabiana de Miranda Moura dos Santos ${ }^{1}$, Cristina Costa Duarte Lanna $^{1}$, Rosa Weiss Telles ${ }^{1}$

1.Universidade Federal de Minas Gerais, Belo Horizonte (MG), Brazil.

*Corresponding author: dccalderaro@gmail.com

\section{BACKGROUND}

Systemic lupus erythematosus (SLE) is a chronic and inflammatory disease and its control depends on adequate management of comorbidities, adoption of a healthy lifestyle and good adherence to treatment. The Waiting Room Project is a patient educational strategy that stimulates patients' autonomy in the management of the disease by teaching important aspects of self-care and treatment, through the elaboration and distribution of booklets.

\section{METHODS}

This extension project, created in 2011, produced 17 booklets about different aspects of the disease and comorbidities, such as smoking, hypertension, diabetes, obesity, physical activity, sun protection, healthy food, oral health, vaccination, pregnancy and osteoporosis. In the years 2020/2021, the project focused on SLE treatment and scientific information about COVID-19. The booklets were written in lay language by medical students and rheumatology professors. The students have also been responsible for the graphic design of the booklets and the illustration and organization of the addressed topics in order to provide more accessible and understandable information. The material is handed out to the patients, while they wait for their medical appointment, by the students and care team, who explain the main topics and answer any questions that may come up. A total of 700 lupus patients, currently under treatment at the university hospital, are involved.

\section{RESULTS}

The booklets are available on the medical school website and are also used as a substrate for the production of publications at the Health Tips section of the project Instagram page. Two booklets about COVID-19 were produced in 2020/2021: one about association between lupus and COVID-19 and another about the treatment of lupus and COVID-19, in order to clarify important aspects of the disease, its impact on lupus patients and to solve questions regarding SLE medications. Other four booklets dealt with aspects of SLE treatment, including adherence to treatment, the use of antimalarials, corticosteroids and immunosuppressants. Information about the drugs, general importance on lupus activity treatment, recommendations and possible adverse events were described.

\section{CONCLUSION}

The current pandemic emphasized the need to health actions to keep the production of academic knowledge and the dialogue between university and community in order to clarify aspects of lupus in the context of the pandemic. The Waiting Room Project, despite the adversities imposed by the pandemic, has been reinvented and has kept its purpose while developing alternatives that maintain and improve health education, making each lupus patient assisted by agents at their own health care.

\section{KEYWORDS}

Systemic lupus erythematosus, Health education, Patient education as topic, COVID-19, Treatment. 